\title{
Correction to: Fabrication of sandwich-structured cellulose composite membranes for switchable infrared radiation
}

\author{
Bin Gu - Kaifeng Liang - Tao Zhang (1) Xuejie Yue - Fengxian Qiu • \\ Dongya Yang $\cdot$ Mingming Chen
}

Published online: 8 November 2019

(C) Springer Nature B.V. 2019

\section{Correction to: Cellulose (2019) 26:8745-8757 \\ https://doi.org/10.1007/s10570-019-02653-0}

In the original article, the sentence "It is observed that CC pattern displays characteristic peaks at $2 \theta$ of $12.69^{\circ}, 20.17^{\circ}$ and $22.05^{\circ}$, which is attributed to the typical (110), (200) and (200) planes of CC I $\beta$ crystalline, respectively." under the section "Preparation of ANPs/C" was published incorrectly.

The correct one is "It is observed that CC pattern displays characteristic peaks at $2 \theta$ of $12.69^{\circ}, 20.17^{\circ}$ and $22.05^{\circ}$, which is attributed to the typical $(1-10)$,

The original article can be found online at https://doi.org/10.1007/s10570-019-02653-0.

B. Gu $\cdot$ K. Liang $\cdot$ T. Zhang $(\bowtie) \cdot X$. Yue

F. Qiu · D. Yang (ه)

School of Chemistry and Chemical Engineering, Jiangsu

University, Zhenjiang 212013, China

e-mail: zhangtaochem@163.com

D. Yang

e-mail: yangdyxxb@ujs.edu.cn

T. Zhang

Institute of Green Chemistry and Chemical Technology,

Jiangsu University, Zhenjiang 212013, China

M. Chen

Department of Physics, Jiangsu University,

Zhenjiang 212013, China
(110) and (020) planes of crystalline CC II, respectively (French 2014)."

\section{Reference}

French AD (2014) Idealized powder diffraction patterns for cellulose polymorphs. Cellulose 21:885-896

Publisher's Note Springer Nature remains neutral with regard to jurisdictional claims in published maps and institutional affiliations. 